Int. J. Dev. Biol. 49: 431-436 (2005)

doi: $10.1387 / \mathrm{ijdb} .041901 \mathrm{gb}$

Developmental Expression Pattern

\title{
Characterization of Hypoxia induced gene 1: expression during rat Central Nervous System maturation and evidence of antisense RNA expression
}

\author{
GABRIELA BEDÓ*,1, MARCELO VARGAS ${ }^{1}$, MARÍA-JOSÉ FERREIRO ${ }^{1}$, CORA CHALAR ${ }^{2}$ and DANIELLA AGRATI ${ }^{1}$
}

${ }^{1}$ Sección Genética Evolutiva and ${ }^{2}$ Sección Bioquímica y Biología Molecular, Facultad de Ciencias, Universidad de la República, Montevideo, Uruguay

\begin{abstract}
Although recent studies have provided a detailed understanding of cellular interactions occurring during the development of the CNS, little is known about the molecular signals which during the peri and postnatal periods ensure its maturation and functionality. Using the mammalian spinal cord as a model, we have designed experiments to examine the main changes in gene expression occurring during this critical transition. In this paper we describe the cloning and characterization of the rat hypoxia induced gene-1 (Hig-1), its expression pattern during spinal cord maturation and in situ localization of its mRNA. We show an increase in Hig-1 expression between $P 1$ and P15 in the spinal cord and a differential spatial pattern. In the P1 spinal cord we observed preferential expression in regions of dorsal laminae II and III and laminae IX ventrally; while in P8, the distribution was more widespread and overall expression was increased. Hig-1 is also widely expressed in the brain. Results of in situ hybridization experiments, as well as particular features concerning ESTs, led us to propose the expression of an antisense mRNA. Primer-specific RT-PCR demonstrates the presence of this aHig-1 transcript whose structure has not yet been characterized. The high homology between putative rHig-1 protein and human- and murine-predicted sequences, as well as its characteristic expression in the Central Nervous System, are indicative of a specific role which could be related to apoptosis signaling during postnatal maturation.
\end{abstract}

KEY WORDS: Hig-1, differential gene expression, CNS, neural postnatal maturation, hypoxia

Functional, cellular and molecular studies suggest a network of signals and remodeling events as responsible for the development of the Central Nervous System (CNS). Many of them, particularly those related to the development of topographically ordered neural connections, occur during the first days of postnatal life (Plenderleith et al., 1992, Coggeshall et al., 1994). Day 1 to 10, of rat postnatal life, are defined as a critical period to reach motoneurones maturity and the establishment of innervation (Walton and Navarrete, 1991, Vinay et al., 2000). During this period, cell death has an important role in adjusting the initial progenitor pool (Kuan et al., 2000), eliminating immature connections and establishing adult patterns of connectivity and function (Katz and Shatz, 1996). Impairment in this critical period can cause irreparable fails in motor and sensitive functions (Clarac et al., 2004). Recent studies have provided a detailed understanding of cellular interactions occurring during the development of CNS (Tessier-Lavigne and Goodman, 1996). But, although some transcription factors (Aizawa et al., 2004), neurotrophins and other growth factors (Bonhoeffer, 1996) as well as guidance molecules have been described, little is known about how these signals might affect the changes in gene expression underlying events during peri and postnatal period to ensure maturation and functionality. With the aim of finding changes in gene expression during maturation of mammalian spinal cord, we have designed experiments of differential display. One of the sequences identified as induced in P8 spinal cord, was cloned and characterized as Hypoxia induced gene-1 ( Hig-1). This gene was previously described in cultured human cervical epithelial cells, as hypoxia induced cDNA, identified through representational difference analysis between oxic and hypoxic cDNAs (Denko et al., 2000). Later, two microarrays analysis had identified Hig-1 in murine culture cells. Jin et al., (2002) have demonstrated a 2.68

Abbreviations used in this paper: aHig-1, antisense Hig-1; CNS, Central Nervous System; EST, expressed sequence tag; HIF, hypoxia induced factor; Hig-1, hypoxia induced gene 1; HRE, hypoxia response element: P1, day one of postnatal life; rHig-1, rat Hig-1. 
fold induction of Hig-1 in neuron-enriched primary cultures from embryonic cerebral cortex exposed for 24 hours to a hypoxic environment. Salnikow et al., (2003) showed that the exposure of mouse embryo fibroblasts in culture to nickel triggered a 13 fold induction of Hig-1. Nevertheless, these genomic analyses reported Hig-1 in lists of induced genes but did not give further information about its expression or putative significance. Salnikow and coworkers also pointed that, as most of hypoxia induced genes, Hig1 would be regulated at transcriptional level, by Hypoxia induced factor (HIF). This transcription factor controls many molecular and physiological responses to hypoxia. Nevertheless, recent expression studies in healthy mice revealed that the function of HIF-1 might reach far beyond hypoxia adaptation: HIF-1 was found to be expressed in diverse normoxic organs within distinct cell types (Stroka et al., 2001). In Nervous System, a model of partial loss of" $H I F-1 \alpha$ function in neurons indicated that $H I F-1 \alpha$ might be required for normal neural differentiation and survival. In divergent fashions, the response to hypoxia might be used by tissues to adjust development in response to local tissue conditions (Tomita et al., 2003). It is demonstrated, in addition, that hypoxia signaling, through HIF-1 dependent or independent transcriptional mechanisms may induce the expression of pro- or antiapoptotic genes (Alvarez-Tejado et al., 2001). As pathway of hypoxia response seems to share signals with the events occurring during normal development, particularly related to differentiation/apoptosis balance, the identification of $\mathrm{Hig}-1$ as differentially expressed during development lead us to look for its significance. In this paper, we characterize rat Hypoxia induced gene 1 sequence and describe its expression pattern during spinal cord maturation and in situ localization of its mRNA. We present, in addition, evidence of antisense mRNA expression that could be the explanation for a refined regulation of its gene expression.

\section{Cloning and identification of rat Hig-} 1

To identify genes that are expressed differentially during early postnatal stages in CNS, we examined mRNA expression of rat spinal cord on day 1 (P1) and 8 (P8) of life, using differential display methods. One of the cDNAs more abundantly expressed in P8 was cloned, sequenced and analyzed against GenBank databases. The analysis revealed high homology with the Hypoxia induced gene 1 (Hig-1), a gene previously submitted for mouse and human and described in cervical cancer cells as induced by stresses of the microenvironment such as low oxygen or low glucose conditions (Denko et al., 2000). Fig. 1A shows nucleotide sequence of a cDNA for this first report of rat Hig-1 (accession number AY062253), a 447 bp sequence including a putative poly $A+$ tail and a signal for

C

R. norvegicus
$R$. norvegicus-sim
$M$. musculus
$H$. sapiens
R. norvegicus
$R$. norvegicus-sim
$M$. musculus
$H$. sapiens

polyA + tail addition 19 bases upstream. Multiple alignment of rat Hig-1 with previously described sequences, constructed using Clustal W (Thompson et al., 1994), revealed a very high homology (93\%) between rat and mouse cDNA (AF141312). Highly conserved tracts are also present when compared with human (AF145385) and the recently described zebrafish (NM_200100) Hig-1 cDNA. An existing rat 1447 bp cDNA (BC059118) that is extended in $3^{\prime}$, is near $100 \%$ homologous to $\mathrm{rHig}^{-1}$ in the shared region. A search against ESTs databases, showed that among 3'ESTs, ten exhibited a polyA + tail coinciding with our cDNA, while

A CTGCTGGCTTCTGATTGGCTGGGGCAAGCAGTGGCCGCAGCGGGCGAAGCCGGT GTTCTAGCACTCGGGGGTGGAGGCCA

1 GAAACCGGCA GGACTGGAAG GGACGTCTCC TCTCCGAAGA СTCTTCAAGA

51 AATCACAATG TCAACCAACA CAGACCTTCC TCTCTCTTCA TACGATGAAG

101 GTCAGGGGTC CAAGTTTATT CGGAAAGCTA GGGAGACACC GTTTGTCCCC

151 ATTGGAATGG CCGGCTTCGC AGCGATTGTT GCATATGGGC TCTACAAGCT

201 GAAGAGCAGG GGAAACACGA AGATGTCTAT TCACTTGATC CACATGCGTG

251 TGGCAGCCCA GGGCTTTGTT GTGGGGGCCA TGACTCTTGG TATGGGCTAT

301 TCCATGTATC AAGAATTCTG GGCCAAGCGT AAGCCTTAGA AGAGCTGGTG

351 GCATGGGAAG TGCTTGCTTT AGTTAGACGT CTCATATTGA GGTTACGTGT

401 tTgtatctac AataAataAc Atgtggtgtt AgAcAaAaAa AAAAAAA

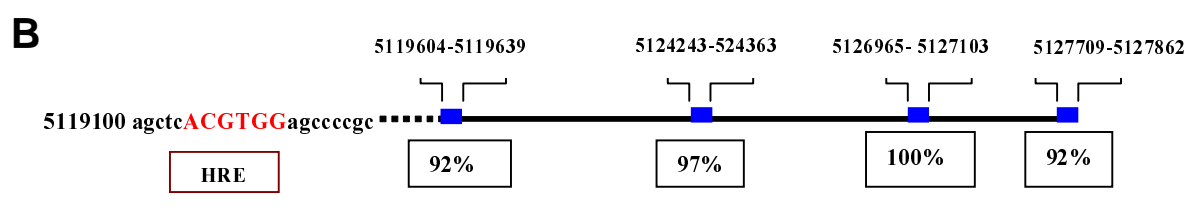

Genomic supercontig in chromosome 8

MSTNTDLPLS SYDEGQGSF IRKARETPFV PIGMAGFAAI VAYGLYKLKS 50 MSTNTDLSLS PYDEGQGSKF IRKAKEKPFV PIGMAGFTAI VAYGLYKLKS 50 MSTNTDLSLS SYDEGQGSKF IRKAKETPFV PIGMAGFAAI VAYGLYKLKS 50 MSTDTGVSLP SYEEDQGSKL IRKAKEAPFV PVGIAGFAAI VAYGLYKLKS 50 RGNTKMSIHL IHMRVAAQGF VVGAMTI IMG YSMYQEFWAK RKP-- 93 RGNTKMSIRL IHMRVAAQGF VVGGMTLGMG YFMYQEFWDK LKP-- 93 RGNTKMSIHL IHMRVAAQGF VVGAMTLGMG YSMYQEFWAN PKPKP 95 RGNTKMSIHL IHMRVAAQGF VVGAMTVGMG YSMYREFWAK PEP-- 93

Fig. 1. Characterization of the rat Hig-1 sequence. (A) Nucleotide sequence of rHig-1 laccession number_AY062253). In grey: primers designed for further studies (amplification, RT-PCR); underlined: putative initiation and stop codon; boxed: putative polyA+ signal. In italic before arrow, $5^{\prime}$ extension, obtained from database, confirmed by RT-PCR with new HEXTF5 primer designed and sequenced. (B) Sequence was compared through Blast, with Rat Genome Resources. We show schematically matching of rHig -1 cDNA with genomic supercontig NW_047803, Rn8_2327 in chromosome 8. Continous black line is genomic sequence. Blue boxes are regions homologous to our CDNA that would correspond to exons. Number under each box represents percentage identity. Position of putative "hypoxia response element" (HRE) based on consensus 5'-ACGTGG- 3', is indicated in upstream sequence. (C) Alignment of putative proteins was performed using the Clustal W program. Identical aminoacids are highlighted. Arrowheads indicate exon/intron boundaries. Ck2 phosphorilation sites (amino acids 3-6 and 10-13) and a myristoylation site (aa 78-83) are boxed. Accession numbers and percentage identity are: R.norvegicus: NP_543178; rat similar to Hig-1 from chromosome X sequence: XP_228571.2 (82\%); M.musculus: NP_062788 (95\%); H.sapiens: T14766 (73\%). 
in eighteen, the polyA+ tail was at the end of the longer cDNA existing in GenBank. This suggests the existence of an alternative polyA+ tail addition signal, generating two mRNAs whose functional significance remains to be investigated. The Hig-1 sequence was also compared with Rat Genome Resources, producing high scoring homology in non-continuous stretches with Rattus norvegicus supercontig in chromosome 8, mapping at $8 \mathrm{q} 32$ (NW_047803, Rn8_2327). In Fig. 1B, we show schematically matching of $r$ Hig-1 with genomic sequence, generating four exons separated by variable long introns. The $1447 \mathrm{bp}$ cDNA previously submitted but not identified as Hig, matches coincidently the same four exons. 5' and $3^{\prime}$ overlapping ESTs allowed us to compose a possible assembled sequence. We designed primers from this sequence and RT-PCR experiments confirmed the extended sequence in 5' (Fig. 1A in italic, Fig. 5). Nevertheless, RT-PCR from P1or P8 spinal cord mRNA, primed with HIG1F and HEXT3 reverse primer to amplify the long cDNA, failed to give the $705 \mathrm{bp}$ predicted product, thus a longer mRNA is not expressed in this tissue at these stages. Our cDNA sequence also exhibited homology (92\% identity) with another supercontig in chromosome $\mathrm{X}$, mapping at Xq31 (NW_048043, RnX_2568), defined as generating a "similar to Hig-1 mRNA". Recently, other homologous genomic sequences were described on chromosome 7 and 3, suggesting that several chromosomal locations could potentially transcribe Hig-1 or similar gene products. Search with TranslateSeq program gave rise to an ORF of $282 \mathrm{bp}$ arising from the second exon that could encode a putative protein of 93 amino acids (NP_543178), as proposed by (Denko et al., 2000) for murine and human Hig-1. In Fig. 1C, an alignment of predicted proteins with Clustal W, exhibited a high homology (95\% and $73 \%$ identity with murine and human sequences, respectively), particularly in the central region of the protein, suggesting the presence of functional domains. However, the search using the Prosite program did not
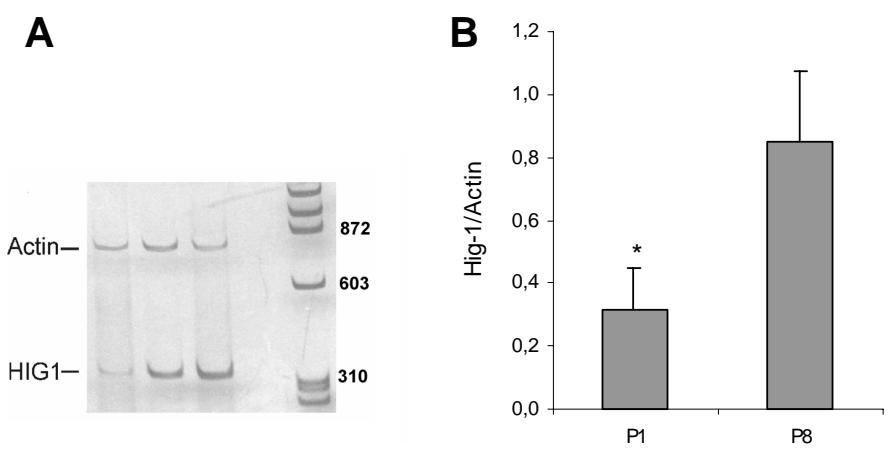

Fig. 2. Hig-1 expression level in rat spinal cord. (A) Silver stained acrylamide gel showing products of duplex RT-PCR reactions from neonatal P1, P8 and P15 RNA (left, middle and right rows respectively). Hig-1 and actin amplicons are 361 and 860 bp respectively. In this experiment $5 \mu \mathrm{g}$ of total RNA was retrotranscribed and a 1/5 dilution of cDNA obtained was used in PCR reaction. Numbers of cycles were 20 for the actin amplicon and 30 for the Hig-1 amplicon lactin primers were added during PCR cycling). The molecular marker is a Haelll Digest of $\phi X 174$ RFI. (B) Relative levels of Hig-1 mRNA expression in P1 and P8 rat spinal cords. Quantification of bands was performed with NIH Image program. The relative estimate is Hig-1/Actin ratio. Histogram is the result of five different experiments. Data are expressed as mean \pm SE and were analyzed by $T$ test for dependent samples (statistically significantly different, ${ }^{*} p<0.05$ ).

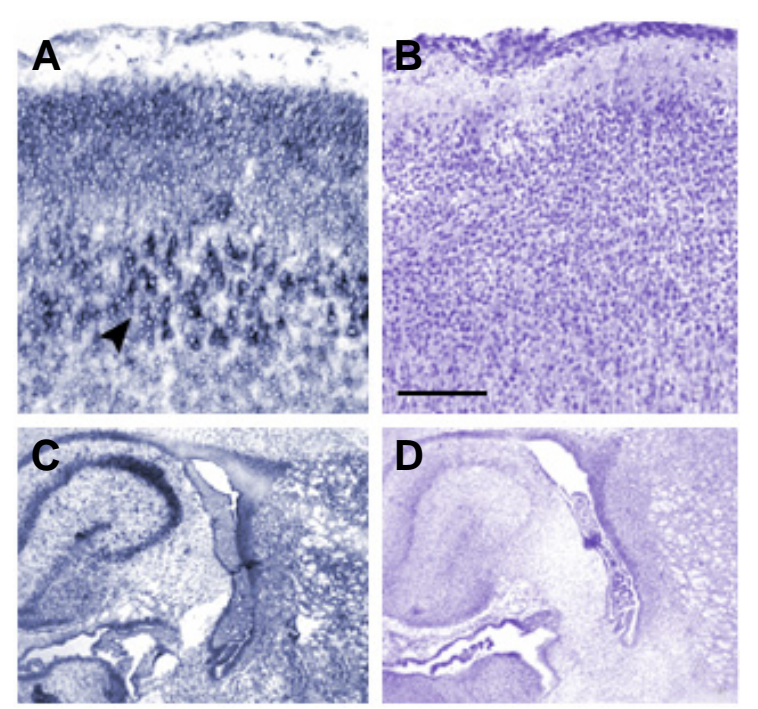

Fig. 3. Localization of $r$ Hig-1 by in situ hybridization in brain. Coronal sections of $P 8$ brain hybridized with antisense probe $(\mathbf{A}, \mathbf{C})$ show widespread signal. Panel (B,D) illustrate the same regions with conventional Niss/ staining. (A), a markedly strong signal is observed in layer V (arrowhead) that is absent in (B) (same region stained with Nissl), suggesting a specific signal. In pane/ $\mathbf{C}$ note the strong signal in the hippocampus and also in striatum. Bars: $A, B, 80 \mu m$ and $C, D, 200 \mu m$.

reveal any known functional motif (only two creatinkinase 2 phosphorilation sites and a myristoylation site were identified as indicated in Fig. 1C). Looking for regulatory motifs, we performed a preliminary analysis of $1000 \mathrm{bp}$ upstream from the longest sequence in chromosome 8, using the Gene Runner program. Even if we could not determine with certainty a consensus TATA box, we characterized a sequence that could represent an "hypoxia response element" (HRE) based on the consensus 5'ACGTG(C/ G)3'(O'Rourke et al., 1997) (Fig. 1B). The recognition of this sequence by HIF-1 transcription factor is essential for the expression of genes implicated in hypoxia and also related with development (lyer et al., 1998, Tomita et al., 2003). A relationship between a HIF-dependent Hig-1 expression and neuronal death during synapsis establishment remains to be tested.

\section{Levels of expression of Hig-1 in the rat spinal cord}

To determine when Hig-1 might be expressed, we analyzed temporal changes in Hig-1 mRNA expression during postnatal development, performing semiquantitative RT-PCR analysis. We designed primers that span putative coding region (highlighted in Fig. 1A). Duplex PCR reactions, using actin amplification as control, were performed under several conditions and cycles number to confirm the results. As it was observed in our previous analysis, Hig-1 expression increases during the first days of postnatal life in the spinal cord (Fig. 2A), encouraging us to look for its significance in CNS. Quantification and normalization of band intensities (Fig. 2B) evidenced that mRNA increase between P1 and $\mathrm{P} 8$ is significant, being $\mathrm{P} 1$ expression approximately $38 \%$ of P8.

\section{Localization by in situ hybridization analysis}

To further characterize its distribution in CNS, a 355 bp sequence amplified with primers previously described was cloned 

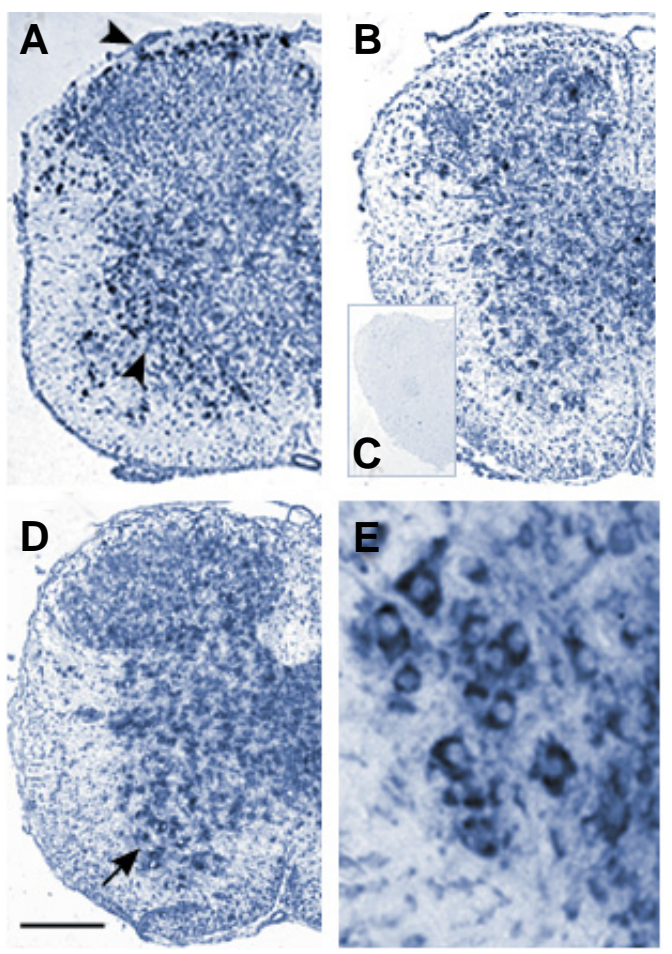

Fig. 4. Differential localization of $r$ Hig-1 in $P 1$ and $P 8$ spinal cord and antisense expression. Transverse sections from lumbar $P 1$ (A) and P8 (B) spinal cord were hybridized with CRNA antisense probe labeled with digoxigenin. (C) Hybridization with non-expressed gene as a negative control. (D) A section of the same region in P8 hybridized with the sense probe. Arrowheads in P1 (A) indicate strong signal in dorsal laminae II and III and ventral laminae IX. Arrow in (D) indicates staining in big motoneurons, magnified in panel (E). Bar: $200 \mu \mathrm{m}$ in $A, B, D ; 600 \mu \mathrm{m}$ in $C$ and 40 $\mu m$ in $E$.

and used to generate digoxigenin labeled sense and antisense probes used for in situ hybridization experiments on brain and spinal cord slices. The general pattern of distribution in the brain suggests a broad and predominant neuronal expression of Hig-1 mRNA, without considerable differences between P1 and P8. Hig-1 displayed signal in mostly all regions, including cerebral cortex, hippocampus, striatum and cerebellum (Fig. $3 \mathrm{~A}, \mathrm{C}$ ). In some cell populations of cortex, particularly in layer $\mathrm{V}$, a very strong signal with Hig-1 probe but not with Nissl staining (Fig. 3 A, B), was suggestive of a high expression. In contrast, in slices of spinal cord (Fig. 4), the pattern of expression changed during first days of postnatal life. By P1, the signal was concentrated mainly in areas corresponding to laminae II and III (Rolando substance) in dorsal horn and laminae IX, ventrally. At P8, the distribution was more widespread and overall expression was increased (Fig. 4A , B), prompting to look for a functional significance. It has been demonstrated that apoptosis is the mechanism of developmental cell death occurring in the CNS (White et al., 1998) and, as we pointed out previously, at least in tumoral cells, hypoxia has been related with apoptosis. Many populations of neurons are known to undergo programmed cell death late in development, after the general framework of the region has been laid. Lowrie and Lawson (2000), quantifying the total number of apoptotic cells, have described a peak just after birth that falls sharply during the following week and concluded that populations of interneurones are undergoing cell death in this period. They also proposed that the factors controlling interneurons survival, occurring well after proliferation, might be unorthodox. These facts raise the possibility that the Hig-1 gene product could be implied in apoptotic or cytoprotective signals (Kuan etal., 2000) during CNS remodeling.

\section{Antisense expression}

For in situ experiments, we generated a sense probe that would represent our control of background staining. To our surprise, this probe gave a strong and specific signal suggesting the expression of an antisense mRNA in this tissue (Fig. 4D). The use of a non expressed gene probe (gooscoid cRNA) as negative control (box c in Fig. 4) as well as the specific expected pattern found with NGF probe (data not shown), ensured that the pattern observed with Hig-1 sense probe did not represent background or artifact features. When we compared the expression based on in situ hybridization, of both antisense and sense probes, we found that the distribution pattern in spinal cord was quite similar, although big motoneuron-like cells (Fig. 4E) were more markedly stained with sense probe. Brain slices gave also a similar and specific pattern with antisense and sense Hig-1 probes. Interestingly, a BLAST search against the EST Database showed that, while Hig-1 cDNA had in most cases an alignment Plus/Minus with 3' ESTs and Plus/Plus with 5'ESTs, 5 out of 42 ESTs sequences showed the reverse situation. Although technical artifacts cannot be excluded, these exceptional alignments could be another support to antisense mRNA expression. On the other hand, we have indicated several genomic locations with homology with our sequence that might be implicated in different transcription events. Further experiments identifying the complete sequence of any antisense mRNA, would clarify different chromosomal loci as responsible for different strand transcription. We notice that, if antisense RNA is present in our extractions, RTPCR results could ultimately reflect a net balance of whole

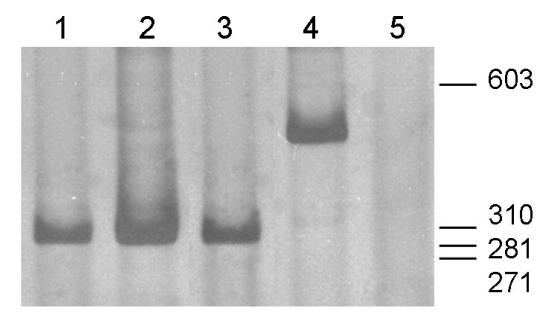

Fig.5. Further characterization of sequence and evidence of Hig-1 antisense mRNA by RT-PCR. Lanes (1-3) Reverse transcription reaction was initiated from $5 \mu \mathrm{g}$ of $P 1$ spinal cord total RNA and PCR performed at same conditions for 34 cycles with HIGF' and HIGR' primers to produce a 290 bp product. In lane (1) the reaction was primed with random primers while in lane (2) for Hig-1 mRNA, RT was with the reverse primer HIG1R and for antisense Hig-1 in lane (3), the RT reaction was initiated with the forward primer HIGIF and then PCR amplified with both primers. In lane (4) MRNA from P8 spinal cord was reverse transcribed with random primers. $1 / 5$ dilution of CDNA amplified with HEXT5F and HIGR' primer pair gave a 425 bp product confirming extension in $5^{\prime}$. Lane (5) is a control reaction without cDNA input. Molecular weight marker is as in Fig. 2. RTPCR products were separated on 6\% acrylamide gel and observed with argentic staining. 
expression including both RNA strands. To distinguish them as well as give evidence of antisense mRNA expression, DNasetreated RNA from $\mathrm{P} 1$ spinal cord was reverse transcribed in separate reactions by use of either the reverse HIG1R or the forward HIG1F primer that would anneal exclusively to one strand mRNA. The resulting cDNAs were then PCR amplified. As illustrated in Fig. 5, PCR reactions yielded in both cases a product of 290 bp confirming an antisense mRNA similar to the sense RNA, at least in this region. Antisense expression is being described in a growing number of genes in eukaryotes (Vanhee-Brossollet and Vaquero, 1998). In many of them, untranslated antisense RNA would participate in regulation through silencing of sense RNA, exerted at many levels of gene expression (transcription, maturation, transport, stability and translation). The regulation of gene expression by endogenous antisense RNAs is likely to be involved in the control of several biological functions including hypoxia response. Even more, a natural antisense transcript complementary to the $3^{\prime}$-untranslated region of HIF- $1 \alpha$ mRNA has been discovered (Thrash-Bingham and Tartof, 1999, Rossignol et al., 2002). The presence of this antisense sequence, as a regulation mechanism must be related with requirements of different and changing levels of $\mathrm{HIG}-1$ protein during maturation of CNS. To further clarify the role of this Hig-1 gene and its product, experiments such as characterization of Hig-1 protein and over expression and repression of gene at cell level remain to be developed. Also, functional studies related with hypoxia or even with apoptosis events participating in neuronal death during synapsis establishment are being performed.

\section{Experimental Procedures}

\section{Animals}

Newborn Wistar male rats were used in this study. The day of birth was considered as postnatal day 1 (P1). All experimental procedures performed were in accordance with local ethical committee.

\section{Cloning and identification}

Sequence was initially isolated by differential display analysis (Matz et al., 1997) with protocol and primers described by the authors, comparing double strand CDNA generated from RNA of P1 and P8 spinal cord. Differential bands were isolated, cloned in a pGEM-T Easy vector (Promega) and sequenced on both strands with the system ABI PRISM 377 DNA sequencer (Perkin Elmer). For comparisons, sequences were analyzed using the Clustal W multiple sequence alignment algorithm provided in the BioEdit software (Hall, 1999).

\section{RNA isolation}

Newborn rats were killed by decapitation on day 1, 8 and 15 after birth (P1, P8 and P15). Spinal cord and brain were removed and immediately processed to isolate RNA by guanidinium thiocyanate/phenol/chloroform extraction as described by Chomczynski and Sacchi (1987).

\section{Semiquantitative RT-PCR}

1 to $10 \mu \mathrm{g}$ of polyA+ or total RNA DNase treated were reverse transcribed using Superscript II (GIBCO) and random primers or oligodT to prime the synthesis. Different dilutions (1/5 to 1/50) of the resulting cDNA were amplified by PCR in a duplex reaction, using actin amplification as internal standard. Amplifications were performed at different cycles from 18 to 34 to determine conditions that ensure that both amplifications were still within the exponentially increasing range (in most cases 24 for actin and 34 for Hig). Primers designed for Hig-1 amplification are as follows:
HIG1F 5'GAAACCGGCAGGACTGGAAG3' and HIG1R 5'CATGCCACCA GCTCTTCTAAGG3'

Those for actin are:

ActF5'GCCCAGAGCAAGAGAGGTATCC3' and

ActR 5'GAGCCACCGATCCACACAGAG 3', giving amplicons of 361 and 860 bp respectively. Identity of these products was confirmed by restriction pattern. Densitometric analysis was performed using the $\mathrm{NIH}$ Image program. Results correspond to five experiments using different cDNA and varying conditions. Data were analyzed by T-test for dependent samples (statistically significantly different, ${ }^{*} p<0.05$ ).

\section{Sequence characterization by RT-PCR}

Once the full-length $\mathrm{Hig}$-1 sequence was defined identifying overlapping ESTs from database, primers were synthesized corresponding to 5' and 3' ends, as follows: HIGF': 5'ACAATGTCAACCAACACAGACC3' and HIGR': 5' GCTCTTCTAAGGCTTACGCTTG3' giving an aplicon of 290 bp within the cloned sequence; HEXT5F: 5'CTGCTGGCTTCTGATTGGC3' to extend sequence in 5' and HEXT3R: 5'TTTCAGAAGCCAGCAAACC3' to identify longer CDNA described in database. To test the existence of antisense mRNA, reverse transcription was performed with specific primer, either HIG1R or HIG1F followed by PCR amplification with HIGF' and HIGR'.

In situ hybridization

Sequence cloned in PGEM-T Easy vector as described below was used to generate cRNA probes. Transcription reactions were performed in the presence of Digoxigenin-UTP according to RNA labeling kit (Roche) instructions. In situ hybridization was carried out on cryosections $(10 \mu \mathrm{m}$ thick), in presence of formamide $50 \%$ with $2 \mathrm{ng} / \mu \mathrm{l}$ of probe at $65^{\circ} \mathrm{C}$ overnight. Post-hybridization treatment was as described previously (Chalar et al., 2003). Afterward, slices were incubated with anti-digoxigenin antibody coupled to alkalin phosphatase Fab fragment $(1: 2000)$ and detected with NBT/BCIP. Microphotographs were obtained with Nikon E800 microscope. Sections were captured digitally using a CoolSNAPPro monochrome digital kit (Media Cybernetics, USA).

\section{Acknowledgements}

The authors would like to thanks Dr.Flavio Zolessi and Dr. Mónica Brauer for help in the use of cryostat, Dr. Yanina Panzera for support in the use of image processing software and Drs. Adriana Parodi, Custodia Garcia and Colin Goding for helpful discussion of manuscript. This work was support by CSIC (Comisión Sectorial de Investigación Científica) Universidad de la República, Uruguay and PEDECIBA.

\section{References}

AIZAWA, H., HU, S.C., BOBB, K., BALAKRISHNAN, K., INCE, G., GUREVICH, I., COWAN, M. and GHOSH, A. (2004). Dendrite development regulated by crest, a calcium-regulated transcriptional activator. Science 303: 197-202.

ALVAREZ-TEJADO, M., NARANJO-SUAREZ, S., JIMENEZ, C., CARRERA, A.C., LANDAZURI, M.O. and DEL PESO, L. (2001). Hypoxia induces the activation of the phosphatidylinositol 3-kinase/akt cell survival pathway in pc12 cells: Protective role in apoptosis. J Biol Chem 276: 22368-74.

BONHOEFFER, T. (1996). Neurotrophins and activity-dependent development of the neocortex. Curr Opin Neurobiol 6: 119-26.

CHALAR, C., RICHERI, A., VIETTRO, L., CHAVEZ-GENARO, R., BIANCHIMANO, P., MARMOL, N.M., CRUTCHER, K., BURNSTOCK, G., COWEN, T. and BRAUER, M.M. (2003). Plasticity in developing rat uterine sensory nerves: The role of ngf and trka. Cell Tissue Res 314: 191-205.

CHOMCZYNSKI, P. and SACCHI, N. (1987). Single-step method of rna isolation by acid guanidinium thiocyanate-phenol-chloroform extraction. AnalBiochem 162: 156-9.

CLARAC, F., BROCARD, F. and VINAY, L. (2004). The maturation of locomotor networks. Prog Brain Res 143: 57-66.

COGGESHALL, R.E., POVER, C.M. and FITZGERALD, M. (1994). Dorsal root ganglion cell death and surviving cell numbers in relation to the development of 
sensory innervation in the rat hindlimb. Brain Res Dev Brain Res 82: 193-212.

DENKO, N., SCHINDLER, C., KOONG, A., LADEROUTE, K., GREEN, C. and GIACCIA, A. (2000). Epigenetic regulation of gene expression in cervical cancer cells by the tumor microenvironment. Clin Cancer Res 6: 480-7.

HALL, T.A. (1999). Bioedit: A user-friendly biological sequence alignment editor and analysis program for windows 95/98/nt. Nucl.Acids.Symp.Ser. 41: 95-98.

IYER, N.V., LEUNG, S.W. and SEMENZA, G.L. (1998). The human hypoxiainducible factor 1alpha gene: Hif1a structure and evolutionary conservation. Genomics 52: 159-65.

JIN, K., MAO, X.O., ESHOO, M.W., DEL RIO, G., RAO, R., CHEN, D., SIMON, R.P. and GREENBERG, D.A. (2002). Cdna microarray analysis of changes in gene expression induced by neuronal hypoxia in vitro. Neurochem Res 27: 1105-12.

KATZ, L.C. and SHATZ, C.J. (1996). Synaptic activity and the construction of cortical circuits. Science 274: 1133-8.

KUAN, C.Y., ROTH, K.A., FLAVELL, R.A. and RAKIC, P. (2000). Mechanisms of programmed cell death in the developing brain. Trends Neurosci 23: 291-7.

LOWRIE, M.B. and LAWSON, S.J. (2000). Cell death of spinal interneurones. Prog Neurobiol 61: 543-55.

MATZ, M., USMAN, N., SHAGIN, D., BOGDANOVA, E. and LUKYANOV, S. (1997). Ordered differential display: A simple method for systematic comparison of gene expression profiles. Nucleic Acids Res 25: 2541-2.

O'ROURKE, J.F., DACHS, G.U., GLEADLE, J.M., MAXWELL, P.H., PUGH, C.W., STRATFORD, I.J., WOOD, S.M. and RATCLIFFE, P.J. (1997). Hypoxia response elements. Oncol Res 9: 327-32.

PLENDERLEITH, M.B., WRIGHT, L.L. and SNOW, P.J. (1992). Expression of lectin binding in the superficial dorsal horn of the rat spinal cord during pre- and postnatal development. Brain Res Dev Brain Res 68: 103-9.

ROSSIGNOL, F., VACHE, C. and CLOTTES, E. (2002). Natural antisense transcripts of hypoxia-inducible factor 1 alpha are detected in different normal and tumour human tissues. Gene 299: 135-40.

SALNIKOW, K., DAVIDSON, T., ZHANG, Q., CHEN, L.C., SU, W. and COSTA, M. (2003). The involvement of hypoxia-inducible transcription factor-1-dependent pathway in nickel carcinogenesis. Cancer Res 63: 3524-30.
STROKA, D.M., BURKHARDT, T., DESBAILLETS, I., WENGER, R.H., NEIL, D.A., BAUER, C., GASSMANN, M. and CANDINAS, D. (2001). Hif-1 is expressed in normoxic tissue and displays an organ-specific regulation under systemic hypoxia. $F A S E B \neq J$ 15: 2445-53.

TESSIER-LAVIGNE, M. and GOODMAN, C.S. (1996). The molecular biology of axon guidance. Science 274: 1123-33.

THOMPSON, J.D., HIGGINS, D.G. and GIBSON, T.J. (1994). Clustal w: Improving the sensitivity of progressive multiple sequence alignment through sequence weighting, position-specific gap penalties and weight matrix choice. Nucleic Acids Res 22: 4673-80.

THRASH-BINGHAM, C.A. and TARTOF, K.D. (1999). Ahif: A natural antisense transcript overexpressed in human renal cancer and during hypoxia. $\checkmark$ Nat/ Cancer Inst 91: 143-51.

TOMITA, S., UENO, M., SAKAMOTO, M., KITAHAMA, Y., UEKI, M., MAEKAWA, N., SAKAMOTO, H., GASSMANN, M., KAGEYAMA, R., UEDA, N. et al. (2003). Defective brain development in mice lacking the hif-1 alpha gene in neural cells. Mol Cell Biol 23: 6739-49.

VANHEE-BROSSOLLET, C. and VAQUERO, C. (1998). Do natural antisense transcripts make sense in eukaryotes? Gene 211: 1-9.

VINAY, L., BROCARD, F., PFLIEGER, J.F., SIMEONI-ALIAS, J. and CLARAC, F. (2000). Perinatal development of lumbar motoneurons and their inputs in the rat. Brain Res Bull 53: 635-47.

WALTON, K.D. and NAVARRETE, R. (1991). Postnatal changes in motoneurone electrotonic coupling studied in the in vitro rat lumbar spinal cord. JPhysio/ 433: 283-305.

WHITE, F.A., KELLER-PECK, C.R., KNUDSON, C.M., KORSMEYER, S.J. and SNIDER, W.D. (1998). Widespread elimination of naturally occurring neuronal death in bax-deficient mice. JNeurosci 18: 1428-39.

Received: September 2004

Reviewed by Referees: November 2004

Modified by Authors and Accepted for Publication: February 2005 